\title{
Pokémon GO! GO! GO! The impact of Pokémon GO on physical activity and related health outcomes
}

\author{
Yaoyue $\mathrm{Li}^{1}$, Yuanchen $\mathrm{Liu}^{2}$, Lei $\mathrm{Ye}^{2}$, Jie Sun ${ }^{2}$, Jianrong Zhang ${ }^{2,3}$ \\ ${ }^{1}$ School of Social Development and Public Policy, Fudan University, Shanghai 200433, China; ${ }^{2}$ Brown School at Washington University in St. \\ Louis, St. Louis, MO, USA; ${ }^{3}$ Department of General Practice, Melbourne Medical School, Cancer in Primary Care Research Group, Primary Care \\ Collaborative Cancer Clinical Trials Group (PC4), Centre for Cancer Research, Faculty of Medicine, Dentistry and Health Sciences, University of \\ Melbourne, Victorian Comprehensive Cancer Centre, Melbourne, Australia \\ Correspondence to: Jianrong Zhang, MD, MPH. Department of General Practice, Melbourne Medical School, Cancer in Primary Care Research \\ Group, Primary Care Collaborative Cancer Clinical Trials Group (PC4), Centre for Cancer Research, Faculty of Medicine, Dentistry and Health \\ Sciences, University of Melbourne, Victorian Comprehensive Cancer Centre, Level 10/305 Grattan St., Melbourne VIC 3000, Australia. \\ Email: jianrong.zhang@unimelb.edu.au. \\ Comment on: Khamzina M, Parab KV, An R, et al. Impact of Pokémon Go on physical activity: a systematic review and meta-analysis. Am J Prev Med \\ 2020;58:270-82.
}

Received: 28 April 2020; Accepted: 17 May 2020; Published: 20 July 2021.

doi: $10.21037 /$ mhealth-20-121

View this article at: http://dx.doi.org/10.21037/mhealth-20-121

Many previous studies have established that a sedentary lifestyle is associated with the risks of disease incidence as well as mortality (1-3). In fact, the World Health Organization (WHO) considered physical inactivity as a leading factor for global mortality (4). In 2013, the WHO proposed the Global Action Plan [2013-2020], aiming to prevent and control noncommunicable diseases; one of the targets is to reduce $10 \%$ of relative prevalence of insufficient physical activity by 2025 (5). This is in consideration of the threat from physical inactivity as well as a high prevalence of physical inactivity and sedentary behaviors $(6,7)$, but also in addition to strong evidence suggesting that the risks of incidence (8) and mortality $(9,10)$ can be reduced by decreasing sedentary time especially when physical activity is improved.

For physical inactivity, useful and sustainable interventions, especially ones that are scalable and applicable to a wide range of audiences, are rare. Recent study has indicated that using digital devices with exercise-related games may increase physical activity (11). As one of the most popular mobile games of all time (12), Pokémon GO maintained an estimated 147 million monthly active users as of May 2018 (13), achieved more than a billion downloads by early 2019 (14), and brought in \$1.4 billion of revenue in 2019, which ranked sixth among free-to-play games (15).
Through catching Pokémon, this location-based augmented reality (AR) mobile game encourages players to "explore real locations and search far and wide" (16). Because of this feature, as well as its wide popularity around the world, whether the game can improve physical activity is of great interest in society.

Accordingly, some related studies have been subsequently conducted and published since the game's release. A recent systematic review and meta-analysis has summarized the results from 16 observational studies and one pre-post study (17). In this review study, the time interval for publication search is from July 2016 to October 2018, involving eight databases. Through comparing Pokémon GO players $v$ s. non-players, and pre- $v s$. post-play time points, the authors concluded that playing Pokémon GO was associated with decreasing sedentary behaviors, as well as increasing walking duration, walking distance and number of steps per day. Some newly published studies after October 2018 also provide evidence of improving physical activity by Pokémon GO $(18,19)$, except one study found that greenway Pokémon GO players may have more stopping and slower pace of walking compared to greenway non-Pokémon GO players (20).

In addition to the increase in physical activity, some Pokémon GO studies found other positive impacts. Playing 
Pokémon GO may lessen psychological distress (21) and increase life satisfaction and vitality, with better family social interactions and community-building $(22,23)$. Playing Pokémon GO may also influence young adolescents' cognitive performance and emotional intelligence, characterized by higher degrees of selective attention, concentration levels and sociability levels, compared to their peers (24).

The aforementioned benefits to some extent help us understand how Pokémon GO motivates players to continually engage in the game. Similar to other games, fun or enjoyment is a common incentive for continuously playing Pokémon GO (25-30). Game motivation could also be explained by the perception that individual wellbeing may result from game experiences via satisfying psychological needs for autonomy, competence, and relatedness, according to the self-determination theory $(31,32)$. Actually, Pokémon GO provides a platform for players to perceive these needs and thus to improve enjoyment through customized avatars, collection and reward system, as well as social feedback from both online and offline interactions with other players $(22,23,28,33)$. A nostalgic feeling from Pokémon fans who love Pokémon movies/serials or previous Pokémon games may also motivate them to try Pokémon GO (34-36) and sustain the engagement in the game $(25,26)$. To attract players' active interaction and involvement, the game developer has been introducing new Pokémon and developing new functions continually such as the Raid Hours, monthly Community Day, the Trading System and the Buddy System, as well as the Go Battle League, during which players earn attractive or exclusive rewards from the game like rare Pokémon (e.g., shiny Pokémon) appearing more frequently on the map or being caught from doing raids. Such new features may further satisfy players' psychological needs.

However, limitations in most of the current Pokémon GO studies should be acknowledged. Same as mentioned in previous commentaries $(37,38)$, the main limitation is still the short-term period of follow-up. In other words, the sustainable, long-run effects of Pokémon GO on improving health remain untested. We take the improvement of physical activity as an example, which normally requires sustainability to achieve. Although admitting the impact of Pokémon GO on improving players' physical activity, some studies have found that the changed volume of physical activity compared to the baseline gradually declined over the research period among players $(34,39,40)$, and that the statistically significant difference in physical activity between players and non-players disappeared after a certain period of game release or installation $(19,41)$. Studies also found that some players reduced time spent on the game or even quit the game during study period $(29,42,43)$. In a sense, dropping out is reasonable if players get bored, lose interest, or feel a lack in time $(28,35,44)$. Accordingly, a short-term follow-up period in the current Pokémon GO studies reflects the concern of how playing Pokémon GO can influence players' health in a long-term period $(37,38)$, especially when maintaining players' active engagement is still required after initial novelty from the game disappears. Secondly, the study design of most of these studies is observational (cross-sectional or cohort study), where there is a lack of sufficient ability to infer a causal relationship between Pokémon GO and some health benefits identified. Accordingly, further studies with a longer period of followup and based on experimental study design are warranted, in order to better understand the influence of Pokémon GO on health.

Specific to the limitations of Pokémon GO studies on physical activity, recall bias might occur when studies use self-report questionnaires rather than mobile pedometer software, to evaluate daily steps. When using mobile pedometer software, however, study investigators should be cautious about the step results as well because some players would use cheat methods like a shaker to "increase" their weekly step results in order to earn better weekly rewards from the game. In this situation, those step results in research may be artificially inflated, so that the comparison results of steps between players and non-players may be biased. Furthermore, a lack of sampling representativeness might occur as well because most of the current studies involve a small sample size or focus on a certain population group like college students, influencing the generalizability to the whole population.

Adverse effects of Pokémon GO should be of concern. Current studies indicated that Pokémon GO could lead to traumatic injuries. A major risk to players is the potential for falls or traffic injuries occurring due to playing the game while walking, cycling, or driving; this is because players become distracted by the game and may ignore surrounding hazards $(45,46)$. However, some studies concluded that most players may still be safe while playing the game: severe injuries account for $10.7 \%$ of all adverse events among Pokémon GO players, consistent to other light-tomoderate outdoor physical activities (47). The incidence rate of fatal traffic injuries is very low, sitting at 0.017 deaths per million (48). Instead of traumatic injuries, the most 
common adverse events among Pokémon GO players are musculoskeletal or skin injuries (68.0\%) (47). Therefore, Pokémon GO may cause similar health injuries, illness and disorders as other video games or physical activities. The most common video-game-related injuries from motiontracking video games are pain syndromes and repetitive strain injuries (RSI) (49). RSI mostly involves hand and upper extremity injuries, such as blistering of the thumb and fingers, as well as soreness of the forearms and shoulders. Smartphone games like Pokémon GO, in particular, place the thumbs at higher risk of injury since most of those games require thumb-based input on smartphone keyboards, which may easily lead to pain syndromes and RSI. Therefore, further Pokémon GO research on RSI seems interesting and relevant to the players. Furthermore, Pokémon GO may also induce psychological and behavioral disorders, like seizure and addiction (49). Apart from these, we also hold concern about the potential risk in the context of the emerging COVID-19 pandemic since Pokémon GO encourages players to exercise outdoors and interact with players in communities.

In conclusion, current studies based on Pokémon GO offer some valuable insight and discussion on the effects of game-based mhealth programs as a way to impact physical, psychological, and social well-being. Pokémon GO, as a widely popular, marketed product, can be seen as a potential indication to solve some health issues, especially given the growing sedentary lifestyles in the world. The success of Pokémon GO can lend a lesson to the current and future mhealth programs about how they can leverage existing popular culture and population interests to achieve health results. Especially given the present COVID-19 pandemic during which social distancing policies have been practised in countries, such game-driven interventions could also play a role in offering incentives for people to keep physically active in a home environment. Ring Fit Adventure for Nintendo Switch might be a good example, which integrates workout routines into its virtual game world; however, we expect more affordable and accessible interventions via using more general digital devices to promote physical activity and maintain well-being. These innovations including Pokémon GO for mhealth may provide more ways to consider the current health problem not just as a topic in academia, but a combination of behavior, market forces, and cultural influences. Therefore, it is important to promote further studies and health solutions that combine and transcend different disciplines to improve public health.

\section{Acknowledgments}

We thank editors and reviewers for their helpful comments. Funding: None.

\section{Footnote}

Provenance and peer review: This article was a standard submission to the editorial office, mHealth. The article did not undergo external peer review.

Conflicts of Interest: All authors have completed the ICMJE uniform disclosure form (available at http://dx.doi. org/10.21037/mhealth-20-121). The authors declare that they and one of the authors in the commented article have a connection to the same affiliation (Brown School at Washington University in St. Louis). However, the author had no role in the conception, writing, or administrative support of this article.

Ethical Statement: The authors are accountable for all aspects of the work in ensuring that questions related to the accuracy or integrity of any part of the work are appropriately investigated and resolved.

Open Access Statement: This is an Open Access article distributed in accordance with the Creative Commons Attribution-NonCommercial-NoDerivs 4.0 International License (CC BY-NC-ND 4.0), which permits the noncommercial replication and distribution of the article with the strict proviso that no changes or edits are made and the original work is properly cited (including links to both the formal publication through the relevant DOI and the license). See: https://creativecommons.org/licenses/by-nc-nd/4.0/.

\section{References}

1. Biswas A, Oh PI, Faulkner GE, et al. Sedentary time and its association with risk for disease incidence, mortality, and hospitalization in adults: a systematic review and metaanalysis. Annals of Internal Medicine 2015;162:123-32.

2. Ku P-W, Steptoe A, Liao Y, et al. A cut-off of daily sedentary time and all-cause mortality in adults: a meta-regression analysis involving more than 1 million participants. BMC Med 2018;16:74.

3. Diaz KM, Howard VJ, Hutto B, et al. Patterns of sedentary behavior and mortality in U.S. middle-aged and older adults: a national cohort study. Ann Intern Med 
2017;167:465-75.

4. World Health Organization. Global recommendations on physical activity for health. Available online: https://www.who.int/dietphysicalactivity/factsheet_ recommendations/en/

5. World Health Organization. Global action plan for the prevention and control of noncommunicable diseases 2013-2020. Available online: https://www.who.int/nmh/ events/ncd_action_plan/en/

6. Guthold R, Stevens GA, Riley LM, et al. Global trends in insufficient physical activity among adolescents: a pooled analysis of 298 population-based surveys with 1.6 million participants. Lancet Child Adolesc Health 2020;4:23-35.

7. Yang L, Cao C, Kantor ED, et al. trends in sedentary behavior among the US population, 2001-2016. JAMA 2019;321:1587-97.

8. Mahmood S, MacInnis RJ, English DR, et al. Domainspecific physical activity and sedentary behaviour in relation to colon and rectal cancer risk: a systematic review and meta-analysis. Int J Epidemiol 2017;46:1797-813.

9. Rees-Punia E, Evans EM, Schmidt MD, et al. Mortality risk reductions for replacing sedentary time with physical activities. Am J Prev Med 2019;56:736-41.

10. Ekelund U, Steene-Johannessen J, Brown WJ, et al. Does physical activity attenuate, or even eliminate, the detrimental association of sitting time with mortality? A harmonised meta-analysis of data from more than 1 million men and women. Lancet 2016;388:1302-10.

11. Bock BC, Dunsiger SI, Ciccolo JT, et al. Exercise videogames, physical activity, and health: Wii heart fitness: a randomized clinical trial. Am J Prev Med 2019;56:501-11.

12. Chamary J. Why "Pokemon Go" is the world's most important game. Forbes 2018. Available online: https:// www.forbes.com/sites/jvchamary/2018/02/10/pokemongo-science-health-benefits/\#2f432d473ab0

13. Tassi P. 'Pokémon GO' is more popular than it's been at any point since launch in 2016. Forbes 2018. Available online: https://www.forbes.com/ sites/insertcoin/2018/06/27/pokemon-go-is-morepopular-than-its-been-at-any-point-since-launch-in2016/\#7449e47dcfd2

14. Iggy. Pokemon GO officially hits 1 billion downloads worldwide. NintendoSoup 2019. Available online: https:// nintendosoup.com/pokemon-go-officially-hits-1-billiondownloads-worldwide/

15. SuperData. 2019 year in review: digital games and interactive media. 2020. Available online: https://www. superdataresearch.com/2019-year-in-review/

16. Pokémon GO. The Pokémon Company. Available online: https://www.pokemon.com/us/pokemon-video-games/ pokemon-go/

17. Khamzina M, Parab KV, An R, et al. Impact of Pokemon Go on physical activity: a systematic review and metaanalysis. Am J Prev Med 2020;58:270-82.

18. Hino K, Asami Y, Lee JS. Step counts of middle-aged and elderly adults for 10 months before and after the release of Pokemon GO in Yokohama, Japan. J Med Internet Res 2019;21:e10724.

19. Ni MY, Hui RWH, Li TK, et al. Augmented reality games as a new class of physical activity interventions? The impact of Pokemon Go use and gaming intensity on physical activity. Games Health J 2019;8:1-6.

20. Beach C, Billstrom G, Anderson Steeves ET, et al. The physical activity patterns of greenway users playing Pokemon Go: a natural experiment. Games Health J 2019;8:7-14.

21. Watanabe K, Kawakami N, Imamura K, et al. Pokemon GO and psychological distress, physical complaints, and work performance among adult workers: a retrospective cohort study. Sci Rep 2017;7:10758.

22. Ewell PJ, Quist MC, Overup CS, et al. Catching more than pocket monsters: Pokemon Go's social and psychological effects on players. J Soc Psychol 2020;160:131-6.

23. Militello LK, Hanna N, Nigg CR. Pokémon GO within the context of family health: retrospective study. JMIR Pediatr Parent 2018;1:e10679.

24. Ruiz-Ariza A, Casuso RA, Suarez-Manzano S, et al. Effect of augmented reality game Pokémon GO on cognitive performance and emotional intelligence in adolescent young. Computers \& Education 2018;116:49-63.

25. Harborth D, Pape S. How nostalgic feelings impact Pokemon Go players - integrating childhood brand nostalgia into the technology acceptance theory. Behav Inform Technol 2019. doi: 10.1080/0144929X.2019.1662486.

26. Ghazali E, Mutum DS, Woon MY. Exploring player behavior and motivations to continue playing Pokemon GO. Inform Technol Peopl 2019;32:646-67.

27. Hamari J, Malik A, Koski J, et al. Uses and gratifications of Pokemon Go: why do people play mobile locationbased augmented reality games? Int J Hum-Comput Int 2019;35:804-19.

28. Broom DR, Lee KY, Lam MHS, et al. Gotta catch 'em all or not enough time: users motivations for playing Pokemon Go and non-users' reasons for not installing. 
Health Psychol Res 2019;7:7714.

29. Wattanapisit A, Saengow U, Ng CJ, et al. Gaming behaviour with Pokemon GO and physical activity: a preliminary study with medical students in Thailand. PLoS One 2018;13:e0199813.

30. Rauschnabel PA, Rossmann A, tom Dieck MC. An adoption framework for mobile augmented reality games: the case of Pokémon Go. Computers in Human Behavior 2017;76:276-86.

31. Deci EL, Ryan RMJPi. The "what" and "why" of goal pursuits: human needs and the self-determination of behavior. Psychological Inquiry 2000;11:227-68.

32. Przybylski AK, Rigby CS, Ryan RM. A motivational model of video game engagement. Review of General Psychology 2010;14:154-66.

33. Yang CC, Liu D. Motives matter: motives for playing Pokemon Go and implications for well-being. Cyberpsychol Behav Soc Netw 2017;20:52-7.

34. Althoff T, White RW, Horvitz E. Influence of Pokemon Go on physical activity: study and implications. J Med Internet Res 2016;18:e315.

35. Rasche P, Schlomann A, Mertens A. Who is still playing Pokemon Go? a web-based survey. JMIR Serious Games 2017;5:e7.

36. Marquet O, Alberico C, Adlakha D, et al. Examining motivations to play Pokemon GO and their influence on perceived outcomes and physical activity. JMIR Serious Games 2017;5:e21.

37. Chaput JP, LeBlanc AG. Pokémon GO: snake oil or miracle cure for physical inactivity? Ann Transl Med 2017;5:S3.

38. An JY, Nigg CR. The promise of an augmented reality game-Pokémon GO. Ann Transl Med 2017;5:S11.

39. Ma BD, Ng SL, Schwanen T, et al. Pokemon GO and physical activity in Asia: multilevel study. J Med Internet Res 2018;20:e217.

\section{doi: 10.21037/mhealth-20-121}

Cite this article as: Li Y, Liu Y, Ye L, Sun J, Zhang J. Pokémon GO! GO! GO! The impact of Pokémon GO on physical activity and related health outcomes. mHealth 2021;7:51.
40. Barkley JE, Lepp A, Glickman EL. "Pokemon Go!" may promote walking, discourage sedentary behavior in college students. Games Health J 2017;6:165-70.

41. Howe KB, Suharlim C, Ueda P, et al. Gotta catch'em all! Pokemon GO and physical activity among young adults: difference in differences study. BMJ 2016;355:16270.

42. Broom DR, Flint SW. Gotta Catch 'Em All: impact of pokemon go on physical activity, sitting time, and perceptions of physical activity and health at baseline and three-month follow-up. Games Health J 2018;7:401-8.

43. Liu W, Ligmann-Zielinska A. A pilot study of Pokemon Go and players' physical activity. Games Health J 2017;6:343-50.

44. Lalot F, Zerhouni O, Pinelli M. "I wanna be the very best!" Agreeableness and perseverance predict sustained playing to pokemon go: a longitudinal study. Games Health J 2017;6:271-8.

45. Barbieri S, Vettore G, Pietrantonio V, et al. Pedestrian inattention blindness while playing pokemon go as an emerging health-risk behavior: a case report. J Med Internet Res 2017;19:e86.

46. Ayers JW, Leas EC, Dredze M, et al. Pokemon GO-a new distraction for drivers and pedestrians. JAMA Intern Med 2016;176:1865-6.

47. Barbero EM, Carpenter DM, Maier J, et al. Healthcare encounters for Pokemon Go: risks and benefits of playing. Games Health J 2018;7:157-63.

48. Ono S, Ono Y, Michihata N, et al. Effect of Pokemon GO on incidence of fatal traffic injuries: a populationbased quasi-experimental study using the national traffic collisions database in Japan. Inj Prev 2018;24:448-50.

49. Pourmand A, Lombardi K, Kuhl E, et al. Videogamerelated illness and injury: a review of the literature and predictions for Pokemon GO! Games Health J 2017;6:9-18. 